\title{
Ruptured corpus luteum cyst in women on anticoagulant: conservative or surgical management a clinical dilemma
}

\author{
Manika Agarwal, Jupirika E. Prybot*, Ashish Dhirasaria
}

Department of Obstetrics and Gynecology, Nort Eastern Indira Gandhi Regional Institute of Health and Medical Sciences, Shillong, Meghalaya, India

Received: 04 September 2017

Accepted: 29 September 2017

*Correspondence:

Dr. Jupirika E. Prybot,

E-mail: jupirika@gmail.com

Copyright: (c) the author(s), publisher and licensee Medip Academy. This is an open-access article distributed under the terms of the Creative Commons Attribution Non-Commercial License, which permits unrestricted non-commercial use, distribution, and reproduction in any medium, provided the original work is properly cited.

\begin{abstract}
Ruptured corpus luteum cyst is a common finding in women of the reproductive age group, but hemoperitoneum in a case of reputured corpus luteum cyst in women on anticoagulants is an uncommon finding. Thus, management in such cases can be done by dose adjustment of anticoagulants. A woman had come to the emergency with complaints of pain distention of abdomen. Her USG showed adenexal mass with hemoperitoneum. She was on anticoagulants. Her coagulation profile was deranged. Patient was managed conservatively with dose adjustment and transfusion of blood and fresh frozen plasma. Hemoperitoneum due to ruptured corpus luteum cyst in reproductive age group have a similar presentation with ectopic pregnancy. In women in this age group pregnancies should be ruled out. Patients on anticoagulants may not require laparotomy and can be managed conservatively.
\end{abstract}

Keywords: Anticoagunants, Corpus luteum, Hemoperitoneum

\section{INTRODUCTION}

Ruptured corpus luteum cyst with hemoperitoneum is commonly seen in women of the reproductive age group. Corpus luteum hemorrhage may occur spontaneously or often triggered by coitus, trauma, exercise, or vaginal examination. ${ }^{1}$

Differential diagnosis usually being ruptured ectopic pregnancy. But ruptured corpus luteum with hemoperitoneum in women on anticoagulants is a rare complication. Its presentation is variable; sometimes it can be massive requiring surgical intervention and blood transfusion.

Patients on anticoagulation are at higher risk for significant severe hemorrhage from ruptured corpus luteum. ${ }^{2}$ Hence an accurate diagnosis based on history, clinical examination and investigation is necessary for proper management.

\section{CASE REPORT}

A 22 year old lady presented with pain abdomen, abdominal distension and breathing difficulty for 2 days, in emergency department of our hospital. She was P3L3 with previous normal delivery 2 years back. Her menstrual cycle was normal and had normal menses 15 days back. She had undergone mitral valve replacement 1 year back and was on anticoagulant warfarin $2.5 \mathrm{mg}$ once daily. One month back she was admitted in neurology ward for 15 days due to ischaemic stroke. On examination her pulse rate was $96 / \mathrm{min}$ and blood pressure $100 / 70 \mathrm{~mm}$ of $\mathrm{Hg}$, pallor was mild. On per abdominal examination there was slight distension and per speculum and per vaginal examination were within normal. Urine pregnancy test was negative. Ultrasound 
showed moderate haemoperitoneum with enlarge adnexa and reported the possibility of ectopic pregnancy. Her haemoglobin was 8 gram \%, beta HCG was negative, coagulation profile was deranged and prothrombin time was 6 times normal. The diagnosis of ectopic pregnancy as suggested by sonography was ruled out due to normal beta HCG and ruptured corpus luteum leading to haemoperitoneum due to coagulation abnormality was considered as provisional diagnosis. Patient warfarin was stopped and 6 units fresh frozen plasma was transfused. After 12 hour patient haemoglobin was 4 gram\%. And pulse rate was 80 per minute, BP $100 / 70 \mathrm{~mm}$ of $\mathrm{Hg}$ and prothrombin time was normal. As vitals were stable it seems that there was no evidence of ongoing intraperitoneal haemorrhage. Patient was transfused 2 units of blood and was provisionally kept prepared for laparotomy in case she developed haemodynamic instability. However, patient remained stable and her haemoglobin build up after blood transfusion. On the fourth day as per advice of cardiac surgeon anticoagulant therapy was reintroduced at a lower dose to prevent any cardiac thrombo embolic episode. She was observed for 15 days in the hospital and was discharged in a fit condition.

\section{DISCUSSION}

In a case study of 3 cases Nupur et al have reported 3 cases of corpus luteum haemorrhage due to congenital or acquired coagulation abnormality, 2 cases were treated with laparotomy. ${ }^{3}$ The third patient was treated with fresh frozen plasma and blood transfusion only. In a similar study on haemoperitoneum associated with ovulation in women with bleeding disorder, Payne $\mathrm{JH}$ et al have reported 3 patients who presented with haemoperitoneum in association with factor 7 deficiency, factor 10 deficiency and cholesterolemia. ${ }^{4}$ They concluded that conservative management with blood products and factor concentrate support was successful in avoiding surgery in 3 of the 5 episodes of bleeding. Chao $\mathrm{W}$ et al has reported a similar case of haemoperitoneum in a 17 years old girl with aplastic anaemia treated with surgery and treatment of blood disease. ${ }^{5}$ Cetinkaya SE et al has reported a case of 24 years old woman with congenital afibrinogenemea with recurrent massive intraperitoneal haemorrhage due to ovulation. ${ }^{6}$ Exploratory laparotomy was done for the first bleeding episode and subsequent episode was managed by fresh frozen plasma with blood transfusion. Ara A et al in their case report also reported two cases where hemoperitoneum was managed conservatively and also various case reports have shown that in case of rupture corpus luteum cyst can be managed conservatively with transfusion of blood and other factors. ${ }^{7-10}$

\section{CONCLUSION}

Haemoperitoneum due to ruptured corpus luteum may be confused with ectopic pregnancy due to similar clinical presentation and sonography picture but may be ruled out due to normal $\beta \mathrm{HCG}$. In patients on anticoagulant therapy with spontaneous massive haemoperitoneum coagulation disorders should be ruled out. If there is any altered coagulation profile supportive treatment with transfusion of blood and fresh frozen plasma may be sufficient without any need for surgery.

Funding: No funding sources

Conflict of interest: None declared

Ethical approval: Not required

\section{REFERENCES}

1. Stenchever M. Comprehensive gynecology. 5th ed. USA, Mosby;2007:460-1.

2. Amal A, Mesdaghinia S. Ruptured corpus luteum cysts and anticoagulant therapy. Int $\mathbf{J}$ Gynaecol Obstet. 2002;76:319-20.

3. Gupta N, Dadhwal V, Deka D, Jain SK, Mittal S. Corpus luteum hemorrhage: rare complication of congenital and acquired coagulation abnormalities. J Obstet Gynecol Res. 2007 Jun 1;33(3):376-80.

4. Payne JH, Maclean RM, Hampton KK, Baxter AJ, Makris M. Haemoperitoneum associated with ovulation in women with bleeding disorders: the case for conservative management and the role of the contraceptive pill. Haemophilia. 2007 Jan 1;13(1):93-7.

5. Sun WC, Li W, Chen QH, Tong JY. Corpus luteum haemorrhage a patient with aplastic anaemia. Obstet Gynecol Res. 2013;39(1):399-401.

6. Cetinkaya SE, Pabuccu EG, Ozmen B, Dokmeci F. Recurrent massive hemoperitoneum due to ovulation as a clinical sign in congenital afibrinogenemia. Acta Obstet Gynecol Scand. 2011 Feb 1;90(2):192-4.

7. Ara A, Malik R, Malla VG. Haemoperitoneum due to ruptured corpus luteum! Managed conservatively2 case reports and review of literature. Int J Reprod Contracept Obstet Gynecol. 2016 Oct;5(10):3622-5.

8. Gupta A, Gupta S, Manaktala U. Conservative management of corpus luteum haemorrhage in patients on anticoagulation: a report of three cases and review of literature. Arch Gynecol Obstet. 2015;291(2):427-31.

9. Tanaka T. Non-operative management of idiopathic ovarian hemorrhage with massive intraabdominal hemorrhage. Osaka City Med J. 1997;43:7-14.

10. Murao H, Kinjyo K, Demura T. Conservative therapy for corpus luteum hemorrhage, a review of 116 cases. Clin Gynecol Obstet 1994;48:568-72.

Cite this article as: Agarwal M, Prybot JE,

Dhirasaria A. Ruptured corpus luteum cyst in women on anticoagulant: conservative or surgical management a clinical dilemma. Int J Reprod Contracept Obstet Gynecol 2017;6:5164-5. 